\title{
Introductory editorial
}

\section{Topical issue: Water management in protected areas}

\author{
Bernardo López-Camacho
}

Received: 8 October 2013/Accepted: 15 October 2013/Published online: 7 November 2013

(C) Springer-Verlag Berlin Heidelberg 2013

The ten articles in this topical issue refer to the concern of management of water resources in protected areas and provide an overview of the methods and techniques available for protecting surface and subterranean water resources, water-linked ecosystems, soils, and the atmosphere. Most of these articles aim to provide criteria and methods for planning the protection of areas of high environmental value at the local, regional and national scales. All illustrate the methodologies discussed with case studies-eight from Spain, one from Ecuador, and one from Cuba. They also include the use of geographic information systems (GIS) and provide a valuable bibliography.

As an introduction to the other nine articles, and owing to its great conceptual and applied research, the work by Martínez Graña et al.-Characterisation of environmental impact on resources, using strategic assessment of environmental impact and management of natural spaces of "Las Batuecas-Sierra de Francia” and "Quilamas" (Salamanca, Spain)—deserves special attention. To characterise the environmental impact of human activities on natural resources in the mentioned protected area, Strategic Environmental Assessment (SAE) and Environmental Impact Assessment (EIA) procedures are used. Using digital maps of the lithology, geomorphology, geotechnics, climate and hydrology, etc. of the study area, maps of surface water quality and aquifer vulnerability to pollution and landfill contamination are produced and superimposed. EIA matrices are then produced. The procedures followed allow for the environmental diagnosis of conservation and

B. López-Camacho $(\square)$

Madrid, Spain

e-mail: blopezcamacho@hotmail.com management plans for protected areas from the outset of their development.

The articles by Cruz, Goy and Zazo-Hydrological heritage in the mountainous areas of Spain: geodiversity inventory and cataloguing of the Sierras de Béjar and Del Barco (in the Sierra de Gredos of the Central System)and of Fernández de Córdova and Pascual AguilarApproaching water management at watershed scale using distributed water balances in the Yanuncay River Basin (Ecuador)_discuss surface water resources. The first of these articles provides an inventory and assessment of 35 locations (areas and points of hydrological concern) of educational, scientific, and tourism interest which together form a hydrological heritage. The aim is that this fragile resource be sustainably managed. The second article reports on the use of a hydrological model based on monthly data values to determine the times of greatest water excess and deficit in an area of important vegetation, thus providing criteria for the conservation of water and the ecosystems that depend on it.

Five articles are concerned with subterranean water resources and the protection of aquifers. Carreño Conde et al., the authors of Building a 3D Geomodel for Water Resources Management: Case study in the Regional Park of the Lower Courses of Manzanares and Jarama Rivers (Madrid, Spain), construct a 3D digital model involving major hydrogeological variables, and identify recharge areas and mining operation sites with a view to water resource protection. Farfán et al., the authors of First outcomes in the definition of groundwater protection zones at the Viñales National Park (Cuba) and surrounding area, discuss a highly karstic area in which potential polluting activities are reviewed, with the aim of protecting subterranean water. The authors make use of a GIS that takes into account vulnerability, human activities, risks and 
variability in recharge, and integrates hydrogram, chemical evolution, and tracer and mathematical model data. An evaluation of aquifer vulnerability in two nitrate sensitive areas of Catalonia (NE Spain) based on electrical resistivity methods, by Díaz et al., suggests that traditional methods for assessing soil vulnerability based on soil classification, drilling of cores, registry analysis, and determination of hydraulic properties (all of which are time-consuming and costly), can be substituted for much less laborious measurements of electrical resistivity and other electrical and electromagnetic methods. The article by Leal et al.-Assessment of groundwater circulation in La Gomera aquifers (Canary Islands, Spain) from their hydrochemical features-examines aquifers in volcanic material. Via springs, such materials provide $60 \%$ of La Gomera's water resources. Volcanic formations, with their secondary and basal aquifers, are at risk of interconnection via wells underlying aquifers and therefore face the possibility of contamination. The authors sought areas of connection via hydrochemical and statistical (principal components and cluster) analysis, but found it hard to produce conclusive results and tell why. Sánchez-Martos and Molina, the authors of Groundwater-wetland ecosystem interaction in coastal lagoon of Almería (SE Spain), describe the use of hydrogeological tools to study the interaction between surface and subterranean water in coastal wetlands, and provide results for an area of great hydrogeochemical variability.
Technical, financial and location criteria for the design of Land Application Systems, by Sanz et al., describes a methodology for the design and treatment of waste water for small or dispersed populations. This methodology combines technical, financial and location criteria, and takes advantage of recent Spanish legislation in this area. Finally, Pascual et al. present Presence and spatial distribution of emerging contaminants (drugs of abuse) in protected agro-ecological systems (L'Albufera de Valencia coastal wetland, Spain). These authors discuss data showing the presence of illegal drugs in the waters of a natural area of coastal lagoons, marshes, dunes and pine forests, surrounded by rice fields and market gardens. These compounds enter this wetland via streams which can contain water (or once contained water) from surrounding towns and urban areas.

These articles are based on presentations made at the first Symposium for the Management of Hydraulic Resources in Protected Areas, held in Viñales National Park, western Cuba, in 2010. They have been expanded based on additional research and/or comments and discussions at the conference itself. The fact that this conference was held in Cuba and that it addresses a critical topic in this increasingly important area of protecting the world's water resources makes this topical issue unique in its field. 